\title{
DOS CENAS FUNDACIONALES: HACED ESTO EN MEMORIA MÍA
}

\author{
TWO FOUNDATIONAL SUPPER TIMES: \\ DO THIS IN REMEMBRANCE OF ME**
}

Sonia Jones León*

\section{RESUMEN}

El siguiente trabajo compara las escenas de las cenas fundaciones: la Última Cena de Jesús y la efectuada en la casa de los Matías con el fin de establecer un diálogo entre ambos momentos, pues el texto literario retoma el intertexto bíblico y lo entreteje en una nueva complejidad narrativa.

Palabras clave: parodia, traición, cena, memoria, mandato.

\begin{abstract}
**
This work compares the scenes of foundational supper times: The Lord's Supper and the one in the Matías' house with the purpose of creating a dialogue between both moments, as the literary text uses the Biblical intertext to mingle it in a new narrative complexity.

Key Words: parody, betrayal, dinner, memory, mandate.
\end{abstract}

* Profesora pensionada, Escuela de Filología, Lingüística y Literatura. Universidad de Costa Rica. Costa Rica.

** Traducción: Lic. Ana Patricia Quirós.

Correo electrónico: soniajonesleon@gmail.com

Recepción: 23/09/13. Aceptación: 24/10/13. 


\section{Introducción}

Este ensayo sobre Ceremonia de Casta me lo debía como asidua lectora de esta novela y a su vez, como católica, estoy siempre invitada a una cena memorial y fundacional de la familia de Cristo. Es imposible que la noción de cena, no convoque todas las cenas inscritas en la cultura occidental y no se diga la del libro más traducido, la Biblia. Además, si no me equivoco, es en Ceremonia de casta en donde todo el tejido diegético es una cena. Asimismo, creo que es la única novela en la literatura costarricense en que esto sucede.

Como se ha interpretado en varios textos, la novela citada narra la cena 1443 de la Familia de Juan Matías que ha sido instaurada por este patriarca como ceremonia para consolidar la casta de los Matías, so pena, de ser excluido del patrimonio económico, si no se cumple con este mandato ceremonial.

Voy a empezar con la cena, última cena de Cristo, según el texto teológico de Joseph Ratzinger (2011) denominado Jesús de Nazareth: desde la entrada en Jerusalén hasta la Resurrección.

Por supuesto, por incompetencia teológica y el matiz ensayístico tomaré algunos aspectos que me guían en la comprensión del gran sacramento de la fe de mi Iglesia (La Santa Eucaristía). Además, el propio Papa Emérito comenta en el apartado 5, al cual denominó " $\mathrm{La}$ última cena" que:

\footnotetext{
Las narraciones sobre la última cena de Jesús y la institución de la Eucaristía [...] están cubiertas de una maraña de hipótesis discrepantes entre si y esto parece impedir el acceso a lo realmente acontecido haciendo inútil cualquier esfuerzo por establecerlo; pero, esto no sorprende tratándose de un texto que se refiere al núcleo esencial del cristianismo y que, de hecho, plantea cuestiones históricas difíciles (p. 125).
}

Me interesa sobre todo lo que se denomina teología de las palabras de la institución: Pablo apunta que Jesús dijo: "Este cáliz es la nueva alianza sellada con mi sangre: haced esto cada vez que lo bebáis en memoria mía".
El teólogo protestante Ferdinand Katten Bush trató de demostrar en 1921 que las palabras de Jesús en la última cena serían el acto fundacional propiamente dicho de la Iglesia. Jesús habría dado con ello a sus discípulos la novedad que les unía y hacía de ellos una comunidad (2011:164).

La pregunta que provoca reflexión teológica es, según Ratzinger ¿Qué es exactamente lo que el Señor ha mandado a repetir? Plantea este teólogo que no manda a repetir la cena pascual (en el caso de que la última cena de Jesús fuera una cena pascual). Recuerda que la cena pascual era una fiesta anual, cuya celebración recurrente en Israel estaba claramente regulada por la tradición sagrada y vinculada a una determinada fecha. $\mathrm{Y}$ aunque en aquella noche no se hubiera tratado de una verdadera cena pascual, según la Ley Judía, sino de la última comida de Jesús en la tierra antes de su muerte, este no es el propósito del mandato de repetir. Así pues, el mandato se refiere solo a aquello que constituía una novedad de los gestos de Jesús de aquella noche: la fracción del pan, la oración de bendición y de acción de gracias y, con ella, las palabras de transubstanciación del pan y del vino. Agrega, Ratzinger, que así se verifica lo que Jesús anunció en el evangelio de Juan 12: 32 "Desde la cruz, Él atrae a todos hacia sí, dentro de sí".

Caracterizando en mayor grado el tema de la Cena de Jesús y su significado, con plena conciencia de que muchos detalles pueden permanecer abiertos, no se puede establecer una investigación histórica, una certeza histórica, pero como apunta Ratzinger, si reconociendo lo acontecido desde la certeza de la fe. Según Juan 1: 14 "La Encarnación de Jesús está ordenada a la entrega de sí mismo por los hombres, y esta a la Resurrección". De otro modo, agrega el teólogo citado, el cristianismo no sería verdadero.

La fe bíblica no relata historias como símbolos de verdades meta-históricas, sino que se funda en la historia que ha sucedido en la faz de la tierra. Si Jesús no dio a sus discípulos su cuerpo y sangre bajo las especies del pan y el vino, la celebración eucarística (la cena) quedaría vacía, sería una ficción piadosa, no una 
realidad que establece la comunión con Dios y los hombres entre sí. (2011: 126)

Otros aspectos que amplían la interpretación de este memorial se exponen en El catecismo de la Iglesia Católica ("catecismo" significa instrucciones):

A saber:

1) $\mathrm{Si}$ los cristianos católicos romanos celebramos la Eucaristía desde los orígenes a pesar de la gran diversidad de épocas y liturgias, es porque nos sabemos sujetos al mandato del Señor; dado la víspera de su pasión "Haced esto en memoria mía" (1 Co, 11: 24-25).

2) La Eucarística es un sacrificio (Este es mi cuerpo que será entregado por vosotros) hace presente el sacrificio de la Cruz, porque es su memorial. En la última cena, quiso dejar a la Iglesia (comunidad) un sacrificio visible y cuya virtud saludable se aplicaría a la redención de los pecados - cuerpo y sangre redentoras.

3) Este memorial sacrificial de Cristo que es la Eucarística (acción de gracias) no es solamente recuerdo de los acontecimientos del pasado, sino actualización (poner en acto). Estos acontecimientos se hacen, en cierta forma, presentes y actuales.

4) El banquete Pascual: la Misa, es a la vez, e inseparablemente el memorial sacrificial en que se perpetúa el sacrificio de la Cruz y el banquete sagrado de la comunión en el Cuerpo y Sangre del Señor. Pero la celebración del sacrificio eucarístico está totalmente orientada hacia la unión íntima de los fieles con Cristo por medio de la Comunión. Comulgar es recibir a Cristo mismo que se ofrece por nosotros.

5) Tomad y comed todos de él: la Comunión. El Señor nos dirige una invitación urgente a recibirle en el sacramento de la Eucarística "En verdad os digo: si no coméis la carne del Hijo del hombre y no bebéis su sangre, no tendréis vida en vosotros".
6) Los frutos de la Comunión:

a) La Comunión acrecienta nuestra unión con Cristo "Quién come mi cuerpo y bebe mi sangre, habita en mí y yo en él" (Juan, 6: 56). La Eucaristía hace la iglesia cuerpo de Cristo- sacramento del Padre (el sacramento hace visible lo invisible) porque aún siendo muchos, un solo pan $\mathrm{y}$ un solo cuerpo somos, pues todos participamos de un solo pan.

b) La Eucaristía entraña un compromiso en favor de los pobres. Para recibir en la verdad el Cuerpo y la Sangre de Cristo entregados por nosotros, debemos reconocer a Cristo, en los más pobres, sus hermanos.

c) Cristo, que pasó de este mundo al Padre, nos da en la Eucaristía la prenda de la gloria que tendremos junto a Él. Sostiene nuestras fuerzas a lo largo del peregrinar de esta vida, nos hace desear la vida eterna y nos une ya desde ahora a la iglesia del cielo y a la Santísima Virgen y a todos los Santos.

\section{Ceremonia de Casta: La cena $\mathbf{1 4 4 3}$}

Don Juan había dejado muy claramente anotadas, en el testamento, las instrucciones para su familia. La casona se mantendría siempre en pie y la propiedad no podría ser vendida por ningún miembro de la familia. Más aún las reuniones vespertinas, a la hora de crepúsculo, cuando los josefinos comienzan a recogerse en sus casas, deberían mantenerse como un rito inviolable, como un encuentro de todos los Matías para mantenerse unidos, para recordar sus nombres, para fijar las imágenes del pasado, para verse en los nódulos de los helechos, para aspirarse en el perfume de los geranios, las azaleas, las rosas, para grabarse en las paredes, en la madera, en el cedro tallado de los muebles (Rovinski, 2006: 22-23).

Esta novela Ceremonia de casta (1975) presenta una estructura compleja por los puntos de vista que van tejiendo la diégesis. La familia legítima del patriarca agrario, Juan Matías y Beatriz Rodríguez, han procreado, en su mansión, varios hijos: Fernando, Anabelle, 
María del Carmen y otros. El patriarca, católico de confesión, preside el ritual en la vieja mansión. Una de las lecturas, le da coherencia a la diégesis, planteando que el núcleo duro de su historia, es la cena 1443, que es a su vez, la última cena de este personaje, que muere horas después en una clínica privada.

Desde afuera de la mansión, el hijo bastardo de Juan Matías (producto de la violación de la madre de aquel, Blanca Rosa, empleada de la finca de los Matías que es designado como el Innominado) contempla los acontecimientos de la cena- ceremonia y en varias ocasiones, alude al hecho de que está ahí para destruir lo que representan los Matías- la vieja mansión e implantar la nueva ceremonia de "violencia" según los vientos que corren. La cena se produce en seis fases organizadas de acuerdo con las normas de la etiqueta establecidas por la sociedad conservadora.

Juan Matías es un católico ahogado por las culpas, que intenta imponerse y anular los deseos eróticos del clan, empezando por los de su esposa Beatriz. Ella pertenece a una familia de Alajuela, sin abolengo, pero que junto con sus primas Albertina y Sonia, han sido instruidas por el tío Manuel, que es experto en libros y prácticas eróticas.

Beatriz sueña en poner en práctica estas enseñanzas y se casa creyendo que el lecho nupcial es el espacio para la realización de lo aprendido. En París, la noche de su luna de miel se dicta la sentencia: "La formulación de un linaje exige el recato, la moderación, el respeto mutuo, el secreto de la alcoba. Una es la ramera; otra, la esposa cristiana" (2006: 79).

Si reflexionamos sobre lo leído, el viejo Matías impone una serie de prohibiciones que atentan contra la libertad, que es una de las cualidades junto con la voluntad, la capacidad de amar y de pensar, propias de los hijos de Dios. A partir de este empoderamiento sobre sus criaturas surge el cuestionamiento de la identidad cristiana de este pater familiae y la del resto del clan, que en la cena, frente a la carne y el vino, son capaces de librarse a la verdad de sus deseos, jugando un papel propio del hipócrita - cuya máscara lo protege de la traición inmediata, pero es indicio de que traicionarán al Todopoderoso y destruían la casta y la casa. Oigamos al Padre:

Para que todo marchara correctamente en esta casa, yo debía imponer el orden, las leyes, la educación, las maneras, el respeto a la jerarquía del linaje. Yo soy el responsable de la seguridad, yo traigo el alimento, el vestido, la educación, yo procuro todo, yo pago, y por eso, exijo obediencia, la explicación de todo movimiento, de todo gesto, de toda idea [...] quiero ser amo de los sueños. Quiero que me rindan cuentas de paisajes, seres, objetos, que acuden cuando la voluntad está rendida, cuanto todo duerme y aparenta la muerte y así, como es la posesión ha de ser la entrega, también: completa, incondicional y definitiva (2006: 126-127).

Este padre ofrece vida material y no es capaz de heredar a su progenie el amor de Dios sino así mismo y a los bienes materiales. Precisamente, en su última cena se fija muy bien en los utensilios y objetos de lujo (todos de marcas europeas) que se repartirían en memoria suya. El pago que se ofrece a cambio de la sumisión es el dinero que da la vida, al satisfacer, lujosamente, cualquier necesidad material. Así, lo piensa Fernando, su hijo mayor que su fuero interno desea rebelarse, esa última noche, pero recapacita pues todo, absolutamente todo se lo debe a Juan Matías:

Alguna vez tendría que hacerlo. Podría despertarle y chorrearle todo su resentimiento y no hacer nada por él cuando lo viera congestionarse, agarrarse el pecho, ahogarse. No hacer nada, más bien reírse, gozar de su dolor, de su agonía. Porque sería un buen pago por los años de humillación, por la agonía de esos años grises de no haber sido alguien más que el falderillo de papá [...] No había conocido nunca la zozobra económica, la angustia, la falta de trabajo. Bajo ese techo nunca faltaron la buena comida, la buena ropa, los libros, los discos, el dinero para las parrandas, para el Country, para los cines, para las bodas, pasear a las novias, en carro, para viajar fuera del país a instruirse, a aprender inglés. Todo lo que era se lo debía a sus padres ¿Cómo podría haber alcanzado a Margarita sin el respaldo económico de don Juan? (2006: 135-136).

Es fascinante constatar que en esta última cena del clan Matías, no hay solo un traidor, sino todos incluido el Padre, lo son. Es precisamente, 
ante la carne y los efectos del vino que dan a conocer sus verdaderos deseos. Es magistral la parodia que permite diseñar el verdadero rostro de estos católicos: "De un platón se fueron sirviendo las tajadas de Chateaubriand rojo, a medio cocer, bañado en su propio jugo [...] la salsa bermaise cubrió la carne como un manto de esperma" (2006:116).

Veamos los "efectos" en algunos de los invitados a la mesa de este señor: "El propio Don Juan partió su carne con lentitud. Sus ojos, hundidos en las bolsas arrugadas de las párpados, brillaron fugazmente, como si esperaran la resurrección de la energía en ese trozo de fibras, venas y sangre" (2006:116).

- $\quad$ Fernando el hijo mayor, el más hipócrita según el Innominado:

Los dientes de Fernando rechinaron al morder la carne. Tenía él ánimo conturbado. Al mascar un trozo bañado en esperma, sintió un cosquilleo que comenzaba en la punta de la lengua, le aprisionaba la nuca y terminaba en el escroto. De pronto, se veía en la cama con una mujer borrosa que gritaba de dolor. La visión espantaba su ánimo y lo hacía sentirse avergonzado ¿sería capaz de lograr esos gemidos, de hacerla sufrir como un bruto? Oiría alguna vez esa súplica, esa solicitud de amor que nunca le habría hecho ninguna mujer (2006: 116).

- María de Carmen, hija de los Matías, infelizmente casada, comulga con su hermano, invirtiendo el valor decencia "impuesto y aceptado" con lo cual mercantiliza el sacramento:

Masticó, rítmicamente, con displicencia, la boca cerrada, veinte veces, hasta formar el bolo que bajaría por la garganta sin dejar rastros; así, corresponde a una mujer decente; así, negándose, con los labios apretados, a que entre su lengua, a besar de esa manera, que es pecado; porque no debe acceder a su exigencia, aunque se trate de su marido [...] cerró los ojos ante lo que podría ser un beso atrevido y el segundo trozo lo masticó con los labios abiertos. Miró a los demás por si acaso, había sido sorprendida. Pero todos estaban como en mundos separados. Entonces María del Carmen sorprendió el pene desvergozando, ofreciéndose a la luz de la lámpara, como una culebra presta a atacar, tinta, marcada de venas. Ahuyentó la imagen perturbadora con un trago de vino y se volvió hacia su hermana Beatriz para hacer un comentario banal (2006: 116-117)

La imagen del cuerpo que se recupera por la carne y la sangre (demi-cuit) remite al sacrificio de cada miembro Matías por la ambición de heredar bienes materiales, cueste lo que cueste. Todos en realidad están casados por interés económico y estatus. El amor - es otra inversión - amor a la apariencia, al estatus, que los aleja del mandato religioso.

- Beatriz, hija, rechaza la carne recién cocida y el vino, ambos símbolos de su oculta pasión:

[...] El trozo seco la mantiene atada, despierta, resignada. Ha rechazado toda posible transferencia hacia el otro. No permite que el cuerpo la domine. No permite que los recuerdos la hagan sufrir, es firme. Quiere ser firme. Con la embriaguez olvidaría la existencia de sus cuatro hijos varones y de su marido. Olvidaría que su personalidad se ha repartido entre todos ellos. Olvidaría ese oscuro resentimiento, de no ser más que un fantasma producido por sus constantes indecisiones (2006: 117-118).

- Esta conciencia permite contrastar con otra hija Matías, Ana Lucía, cuya conducta es más libre pero más calculadora:

Ana Lucía saló más su carne, desplegó la servilleta de lino de la panera para servirse una tajada de pan, untó más esperma sobre lo crudo, sorbió el vino, masticó y habló. Mientras sus palabras acudían como un torrente, su mente se ocupaba de los cálculos. De paso, el Rosenthal de la herencia, el antiguo bodegón que sería suyo, las lámparas que iluminarían la nueva residencia comprada con el dinero proveniente de la sexta parte de la herencia, las copas de cristal que nadie, solo ella, se atrevería a reclamar [...] mientras Remigio escalaría sus puestos en el Partido (cueste lo que cueste) para que todo el mundo aprenda a respetarlo, los respete y hable de ellos. Y hoy, aunque se ha enfriado el amor, todas las demás cosas contribuirían a compensarlo. Y a Ana Lucía no le haría falta Remigio, porque hombres no le faltarían en sus largos tiempos de ocio, gozaría de la carne en un nido reservado, saboreando los besos de su amante [...] Puso más salsa y tomó más vino (p. 119).

Este mosaico de personajes "cada uno en su mundo" en realidad forman una comunidad basada en los intereses puramente materiales. 
Aún el nieto amado, Raulito, se enmascara: "Y Raúl se estremece con la imagen fugaz, aparecida en el cristal de la copa, como se estremeció de placer y miedo aquella vez pegado a la ventana que daba al huerto, espiando la intimidad de las muchachas" (2006:121).

Esta cena ceremonial de casta es una inversión total de la finalidad de la vida cristiana. Esta familia forma comunidad por el amor al dinero y al poder.

La misión en la tierra que cree haber cumplido Juan Matías, solo es del orden de lo material. Además, de la violencia que ejerce contra su clan y él mismo, violenta los mandatos en relación con el prójimo. La primera víctima es la campesina que viola y embaraza y el no-lugar que le asigna al fruto de esa violación. Además, Juan Matías es un corrupto, avaro, prestamista como su gemelo (inconsciente acusador que le provoca alusiones culpables). Su conciencia - el Innominado- reafirma el apego a lo terrenal y al patrimonio construido

\footnotetext{
Progenie demasiado humana la nuestra, viejo. Demasiado hincada en la tierra para soñar con las alas que remontan montañas, que atraviesan nubes, que se posan en el cielo. Metidos en sus jaulas de lujo, calculan pirámides humanas y libretas de ahorro, cargan anteojos mágicos para deformar la pestilencia para torcer, torcer la virtud, para simular la ignorancia y corromper todo el aire que respiramos (2006:71).
}

Los alimentos de esta cena ceremonial, la última, del patriarca y los descendientes, tiene como plato principal la carne término medio (es decir sangrante) y además, la bebida principal es el vino tinto. Carne y vino son los alimentos que nutren la ambición de estos cristianos devorados por la codicia y el deseo de destruir al Padre. Todos y todas piensan ante la carne - en lo que desearían hacer que en términos generales es traicionar al Padre... liberarse de su poder, solo que esperan pacientes la muerte natural del Patriarca, para ser lo que anhelan y destruir así la casta y la mansión.

Estos alimentos al permitir que fluyan los verdaderos deseos de los "cenantes", en lugar de unirlos al Padre, los separan. Como cabeza de familia, pequeña iglesia, Juan Matías no permite la conversión de los suyos y por lo tanto, su salvación. Al contrario, su mandato ratifica su alejamiento de su identidad de cristiano y la de los suyos. El reino que propicia con su ejemplo es el de este mundo y su necedad le impide el arrepentimiento. Solo le da espacio a la culpa y convierte la mansión en un gran escenario en que cada miembro porta su máscara. La cena 1443, a la que asisten doce, es la comedia por antonomasia de los doce traidores que comen para hacer evidente el fruto de su maldad.

Finalizadas las cenas de las narraciones convocadas, aparece la muerte de los instauradores del memorial. Juan Matías muere rodeado de los suyos; Cristo, abandonado y traicionado.

La mansión de los Matías es demolida para "romper las ataduras de la memoria de un pasado muerto, inútil, que pretendía reproducirse por años y años hasta la eternidad, como si los huesos corroídos de los muertos quisieran salir de sus tumbas para imponer un nuevo orden" (2006: 220). Todos abandonaron el ritual y solo Fernando fue el que tuvo un comportamiento decente en el acto de la repartición de la herencia:

Porque has de saber que doña Beatriz tomó las disposiciones pertinentes para distribuir en vida todo lo que legaste, y cerró los ojos a las tropelías cometidos por hijas y yernos con las propiedades, especialmente, como te conté ya con la mansión que iba a abrigar la continuidad de tu linaje (2006: 211).

En mi Iglesia, a través de los siglos es evidente las serias desviaciones del mandato del Amor. Ya muchos templos han sido cerrados y algunos se alquilan para espectáculos profanos. De cada diez costarricenses que se declaran católicos, solo uno va a misa, y muy pocos aceptan cenar.

La apariencia nos consume y la ignorancia del significado de la Eucarística nos devora. Bautizamos, confirmamos y preparamos la progenie para su primera cena. Hasta ahí cumplimos con un ritual que se ha vuelto absolutamente social y por lo que "potis". Si bien es cierto, es incomparable la Cena del Señor y la Cena de los Matías, que parecidos resultamos todos al final. 
La gran alegría es que hay tiempo de volver al camino:

En la comida cristiana confluyen tres grandes realidades últimamente unidas; la fe, la conversión, la salvación. Ahora bien, la conversión tiene como signo muy palpable y concreto la lucha contra la pobreza, liberar al pobre, compartir con él los bienes. La Eucarística debe ser un momento privilegiado de ese compartir mesa y dinero (2000: 103).

He querido con esta reflexión comulgar con todos los amantes de la literatura costarricense, convocando dos figuras muy importantes en mi vida - dos judíos - Jesús y Samuel. Gracias.

\section{Bibliografía}

Conferencia Episcopal de Costa Rica. 2000. Catecismo de la Iglesia Católica. San José: Editorial CENACAT.

Maldonado, Luis. 1997. Eucaristía en devenir. Santander: Editorial Sal Terrae.

Ratzinger, Joseph. 2011. Jesús de Nazareth. Madrid: Editorial encuentro.

Rovinski, Samuel. Ceremonia de Casta. 2006. Editorial de Costa Rica.

\section{@ $\odot \Theta \Theta$}

Este obra está bajo una licencia de Creative Commons Reconocimiento-NoComercial-SinObraDerivada 4.0 Internacional. 
